\title{
Factors Affecting English Test Scores: A Case Study in Taiwan
}

\author{
Shan-Shan Kung \\ The Department of English Studies, Ming-Dao University, Zhanghua, Taiwan R.O.C.
}

Email address:

san00720@hotmail.com

To cite this article:

Shan-Shan Kung. Factors Affecting English Test Scores: A Case Study in Taiwan. Education Journal. Vol. 4, No. 1, 2015 , pp. 33-36. doi: 10.11648/j.edu.20150401.17

\begin{abstract}
Globalization has been a huge and important impact to almost every industry in all countries. To catch up the trend of globalization, having the most popular language, the English, well trained is particularly important. The study examines factors that affect English test scores for Taiwanese college students using a multivariate regression analysis. The result indicates that gender is an influencing variable with significant impact. Not surprisingly, time spent in outside reading and English study can enhance test scores significantly. Although the test score is less affected by per study hour, it is likely to be much more important than gender. The reason is that influence from gender is fixed since it only affects the scores once, but the effects from study hours can be cumulated. In addition, another factor having considerable impact on test scores is the time spent in soap opera. It is positively related to the test scores but its influence to scores is much smaller. However, the effect can still be large due to its cumulative property. Compared to time spent in moves, time spent in soap opera is more effective than in moves in terms of test scores improvement. The study also implies some potential study strategies that may benefit students either in study efficiency or class and test performance. A typical strategy is efficient allocation of study hours. Time allocation on various subjects is important due to the concern of diminishing return. Therefore, if students can optimize their marginal contribution from study, they may obtain the highest return (scores) from the same input (study hours).
\end{abstract}

Keywords: English Test, Multivariate Regression Analysis, College Student, Taiwan

\section{Introduction}

After more and more interactions among countries' economic, education, medical, agricultural and many other activities, something affecting one nation significantly is more easily influencing the rest of the world. Globalization has been a huge and important impact to almost every industry in all countries. The United States, probably the strongest country, plays an important role in business, science, technology and education and thus, English became important because people needed to enhance their English abilities to maintain their international relationships with other countries and people (Modiano, 2001). To catch up the trend of globalization, having the most popular language, the English, well trained is particularly important. Therefore, English is the required second language for freshmen in all university and students must achieve a certain level in some English tests, attempting to enhance students' ability to understand the latest news and information releasing from the United States and Europe. In addition, the scores from uniform tests may provide a clue indicating the potential of students catching those information. As consequences, many companies concerning the impacts from globalization want to find people who can help them succeed in this global competition. For this reason, many companies have announced that all clerks and salesperson should have passed the English tests such as TOEIC to obtain the job position. Due to all of these reasons, the study examines factors that affect English test scores for Taiwanese college students using a multivariate regression analysis. This study contributes on how teachers understand crucial factors influencing the scores of students, evaluate their efficiency of teaching effort, and provide some potential study strategies that may benefit students in either study efficiency or class and test performance.

\section{Related Works}

Many studies (Harris and Hodges, 1995; Street, 1995; Venezky, Wagner, and Ciliberti, 1990) have pointed out those successful strategies for engaging (reading), producing (writing) and talking about texts across the content areas and 
levels of education. Moreover, Gee (1999) also discussed that a central strategy for improving the literacy education of marginalized students entails making these students social theorists of social languages. Besides, Fairclough (1995) found that people's critical language awareness and the development of their own language capabilities and practices had an intimate relationship.

Hanushek (1986) found that one problem is involved in many studies is the variables representing school and teacher "quality" are typically very crude. For example, Dan and Domonic (1996) showed that degree level alone does not distinguish between colleges of differing quality, nor when the degree was granted, nor does it convey any information about college major, certification requirements fulfilled, or subsequent professional development. Our implementation of more education-related variables may be more useful to investigate the missing points raised by previous studies. Another idea was pointed out by Monk and King (1994) that teacher subject matter preparation in mathematics and science does have some positive impact on student achievement in those subjects. However, Ehrenberg and Brewer (1994) thought that Measures of the selectivity of teachers' colleges have also been shown to be positively related to student achievement. Therefore, we incorporate several important factors that may have crucial influences on students' learning efforts which later translating into test scores. Since the score of uniform English tests is not incorporated in the previous studies, which is an important test for almost Asia countries, the incorporation of this factor may provide useful information on how it is affected by students' behavior.

\section{Model Specification}

The study utilizes a multivariate linear regression model to examine the relationship between a dependent variable, $Y$ (the TOEIC test score) and seven predictor variables $\mathrm{X}_{1}$ (Gender), $\mathrm{X}_{2}$ (English study time), $\mathrm{X}_{3}$ (outside reading), $\mathrm{X}_{4}$ (interest in soap opera), $X_{5}$ (hours in soap opera), $X_{6}$ (interest in movies) and $X_{7}$ (hours in movies).

In the multiple linear regression model,

$\mathrm{E}\left(\mathrm{Y} \mid \mathrm{X}_{1}=x_{1}, \mathrm{X}_{2}=x_{2}, \ldots, \mathrm{X}_{7}=x_{7}\right)=\beta_{0}+\beta_{1} x_{1}+\beta_{2} x_{2}+\ldots+\beta_{7} x_{7}$

Thus,

$Y_{i}=\beta_{0}+\beta_{1} x_{1 i}+\beta_{2} x_{2 i}+\beta_{3} x_{3 i}+\beta_{4} x_{4 i}+\beta_{5} x_{5 i}+\beta_{6} x_{6 i}+\beta_{7} x_{7 i}+e_{i}$

where equation (1) describes the basic form of the multivariate regression model, $e_{i}$ is random fluctuation (or error) in $\mathrm{Yi}$ and is such that $\mathrm{E}\left(e_{i}\right)$ equals to 0 . In this case the response variable $\mathrm{Y}$ is predicted from 7 predictor variables $\mathrm{X}_{1}$, $\mathrm{X}_{2}, \ldots, \mathrm{X}_{7}$ and the relationship between $\mathrm{Y}$ and $\mathrm{X}_{1}, \mathrm{X}_{2}, \ldots, \mathrm{X}_{7}$ is linear in the parameters $\beta_{0}, \beta_{1}, \beta_{2}, \ldots, \beta_{7}$.

\section{Variable Description}

Based on actual class survey data, we obtain 76 effective observations. These observations are randomly selected from classes to avoid data selection bias. The dependent variable $\mathrm{Y}$ is TOEIC test score where the independent variable $\mathrm{X} 1$ is gender, X2 is time spent in English study, X3 is outside reading, X4 is interest in soap opera, X5 is hours spent in opera, $\mathrm{X} 6$ is interest in movies and $\mathrm{X} 7$ is time spent in watching moves. The summary statistics indicate that only variables $\mathrm{X} 1, \mathrm{X} 2, \mathrm{X} 3$ and $\mathrm{X} 5$ are significant. Time spent in watching movies does not contribute to students' English test score. Summary statistics of these variables are presented in table 1 . These variables are selected based on their potential influences on students' test performance. However, their significance on the real tests will be examined in the next section of this study.

Table 1. Summary Statistics

\begin{tabular}{llllll}
\hline Variable & Observation & Mean & Std. Dev. & Minimum & Maximum \\
\hline Y & 76 & 530.8158 & 164.5299 & 165 & 950 \\
X1 & 76 & 0.7368421 & 0.443273 & 0 & 1 \\
X2 & 76 & 1.934211 & 1.074995 & 0 & 4 \\
X3 & 76 & 0.3815789 & 0.489002 & 0 & 1 \\
X4 & 76 & 0 & 0 & 0 & 0 \\
X5 & 76 & $5,276,316$ & 5.824886 & 0.5 & 35 \\
X6 & 76 & 0.0394737 & 0.196013 & 0 & 1 \\
X7 & 76 & 4.560526 & 6.606645 & 0 & 40 \\
\hline
\end{tabular}

\section{Regression result and Discussion}

Table 2. Statistical Result

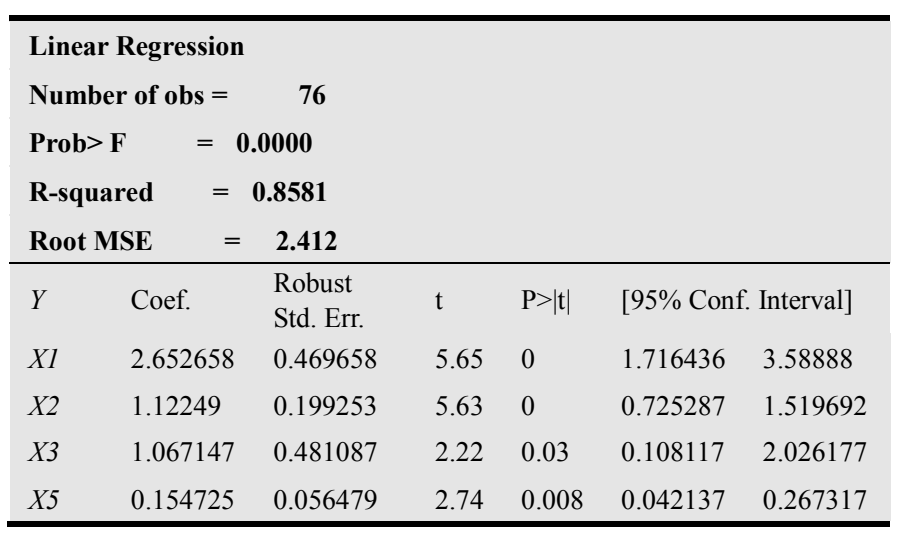

The R-square is 0.858 , which shows that the data descript the model pretty well and the regression result shows that if the student is female, the test score will be $2.65 \%$ higher than male. This implies that gender can affect test scores significantly. The potential explanation of this may be that female is more carefulness in nature and therefore, they may not ignore important hints from questions or make fewer mistakes on reading or understanding the problem sets. Although gender is not changeable, it does not affect test scores a lot and male students can do as well if pay also pay enough attention on questions. Every 1\% increase in English study hour enhances about $1.12 \%$ of test scores. Like gender, study time is very important in test performance. Although the test score is less affected by per study hour, however, it is 
likely to be much more important than gender. The reason is that influence from gender is fixed (that is, gender only affects the scores once), but the effects from study hours can be cumulated. The more time you spend in studying, the higher scores you are likely to obtain. Of course, we also need to remember the rule of diminishing return, which says that the marginal product will decrease for additional input. In other words, the more time the students spend in studying, the higher scores they will get, but the increment of scores will be less and less. It can be thought of the decreasing of study efficiency. Outside reading also affect the English test score significantly as if students read more than class assignments, their test scores is likely to be $1 \%$ higher than those who do not like to read outside materials. This factor is like gender for their one time influence. However, since the data does not include the time spending in outside reading, the result cannot say to what extent the per hour of outside reading may influence test scores. Time spending in watching soap opera also benefits test scores. When hours spending in watching soap opera increases by $1 \%$, their test scores are likely to increase about $0.15 \%$. Like study hour, hours for soap opera is positively related to the test scores and this effect will be large if students spend many hours in this. However, readers still need to remember the rule of diminishing return, indicating that the scores will not increase at the same rate. It is interesting to note that watching movies does not help to enhance test scores. The possible explanation for this may be that compared to soap opera, movies may be les related to the daily life, which is the core objective of TOEIC English tests. The regression model indicates that only gender, outside reading, study time and hours in watching soap opera affect the English test scores significantly. This implies that when teachers try to enhance students' English test score, they may need to put more attention on male because male students are more likely to get lower scores. It is not surprising that study hour is significantly positively related to the test score because effort usually can be transformed into fruits. In addition, encouraging students to develop habits such as reading other English materials such as comics or novels, watching soap opera can be feasible ways that increase students' test scores. Throughout this study, it is clear that the one important study strategy is efficient allocation of study time. This means is student can allocation their time carefully and efficiently rather than pursue certain aspects, they may get higher scores in reading, listening, writing and oral speaking. If they only spend time in one or two fields, they may get high scores but low in rests, due to the marginal contribution of time spending in one field will decrease as study hours increase.

\section{Conclusion}

Performance of internationally recognized English tests has now becoming an important indicator for winning scholarship, obtaining a job and getting a promotion. Therefore, more and more students are trying to get a good score on these tests. In Taiwan, the most popular English test is TOEIC because it is more related to daily communication, social life and business.
Therefore, the study aims to find factors affecting students' TOEIC test score using multiple variable regression analysis.

The result shows that the data descript the model pretty well and only gender, outside reading, study time and hours in watching soap opera affect the English test scores significantly. Female, in general, obtain higher English test scores than males due to their carefulness in reading and answering. However, gender does not affect scores lot and is potentially offset by other factors such as effort and talent. Study hour and time spend in soap opera have smaller effects on test scores, compared to the gender and outside reading. However, their effects can be cumulated, resulting in substantial score differences. The more time you spend in studying, the higher scores you are likely to obtain. But the existence of the rule of diminishing return says that the marginal product will decrease for additional input, implying that the score increment for the last hour students spend in studying may be close to zero. However, this still implies that effort placed by students is able to offset the natural difference such as gender, whose one time effect is large. Based on the consideration of the rule of diminishing return, professors can encourage students to allocate their time efficient to obtain higher scores rather than putting all the time on a single aspect. It is interesting that watching movies does not help enhance English test scores. The possible explanation for this may be that the English movies imported to Taiwan are less relative to our daily life and terms used in the movies cannot be well absorbed by their audiences. Future extension of this study may include the analysis of categories of imported movies to examine if our assumption is correct or not and to quantify what kinds of movies may do well for students. The extension can also be applied on the score improvement rate on outside reading to see if additional hour or book from outside reading provides significant benefits on test performance. This requires an intensive evaluation and is out of scope of this study.

\section{Acknowledgments}

Thanks the great help from Dr. Chih-Chun Kung for his great help in providing insights on economic modeling and interpretation. I also thank the financial support of National Natural Science Foundation of China (41161087).

\section{Reference}

[1] N. Modiano, "Linguistic imperialism, cultural integrity, and EIL,” ELT Journal, 2001, 55(4), 339-346

[2] T.L. Harris and R. E. Hodges, (Eds.). The literacy dictionary: The vocabulary of reading and writing, 1995, Newark, DE: International Reading Association.

[3] B. Street, Literacy in theory and practice, Cambridge: Cambridge University Press, 1995.

[4] R. L. Venezky, D.A.Wagner, and B. S. Ciliberti, (Eds.), Toward defining literacy. Newark, DE: International Reading Association, 1990. 
[5] J. Gee, "Learning language as a matter of learning social languages within discourses", Paper presented to the annual meeting of the American Educational Research Association, Montreal, Canada, 1999.

[6] N. Fairclough, Critical discourse analysis: The critical study of language. London: Longman, 1995.

[7] E. A. Hanushek, "The economics of schooling: production and efficiency in the public schools," Journal of Economic Literature, 1986, XXIV (3): 1141-78.

[8] D. G. Dan and J. B. Dominic, "Evaluating the effect of teacher degree level on educational performance." Reports-Evaluative/Feasibility (142), 1996.
[9] D. H. Monk and J. King, "Multi-level teacher resource effects on pupil performance in secondary mathematics and science: the role of teacher subject matter preparation." In R. G. Ehrenberg, ed., Choices and Consequences: Contemporary Policy Issues in Education, 1994, pp. 29-58. Ithaca, NY: ILR Press.

[10] R. G. Ehrenberg .and D. J. Brewer, "Do school and teacher characteristics matter? Evidence from High School and Beyond", Economics of Education Review, 1994, 13(1): 1-17. 